\title{
Enzyme polymorphism in Pseudomonas aeruginosa strains recovered from cystic fibrosis patients in France
}

\author{
Christian Martin, ${ }^{1} \dagger$ E. Fidelma Boyd, ${ }^{2}$ Roland Quentin, ${ }^{1}$ Pascal Massicot ${ }^{3}$ \\ and Robert K. Selander ${ }^{2}$
}

Author for correspondence: Roland Quentin. Tel: +332474780 56. Fax: +33247473812. e-mail: quentin@pop.med.univ-tours.fr

\footnotetext{
1 Département de Microbiologie Médicale et Moléculaire, Unité de Bactériologie, $\mathrm{CHU}$ Bretonneau, 37044 Tours Cedex 1, France

2 Institute of Molecular Evolutionary Genetics, Pennsylvania State University Park, PA 16801, USA

3 Centre Héliomarin, 19 Boulevard Félix Faure, 17370 Saint Trojan-lesBains, France
}

\begin{abstract}
Each of 314 strains of Pseudomonas aeruginosa recovered from 87 French cystic fibrosis (CF) patients was typed by multilocus enzyme electrophoresis to investigate the genetic diversity, the relatedness and the molecular epidemiology of strains isolated from cases of chronic pulmonary colonization. Comparison of allele profiles at 18 enzyme loci identified 17 electrophoretic types (ETs). Of the 314 isolates, $290(92 \%)$ were either ET1 $(n=127)$ or ET2 $(n=$ 163), which differed only at the shikimate dehydrogenase (SKD) locus. The mean genetic diversity $(H)$ was $0 \cdot 138$. These results suggest that there is crosscolonization between patients and/or that two predominant groups of strains are able to colonize French CF patients. Sequential isolates collected from 18 patients during a period of 12-28 months were analysed to assess genomic variability and its relationship to clinical outcome. Six patients were colonized by a stable strain. For the others, double infections or changes in colonization over time were observed. No relationships were detected between the clinical outcome and the persistence of stable isolates, the emergence of transient superinfecting variants, the presence of multiple ETs or the shift of ET during the monitoring.
\end{abstract}

Keywords: multilocus enzyme electrophoresis, MLEE, electrophoretic types, cystic fibrosis, $P$. aeruginosa

\section{INTRODUCTION}

Pseudomonas aeruginosa has a wide environmental and ecological distribution. It is an opportunistic pathogen which particularly infects patients presenting the following predisposing factors: infected burns, immunosuppressive treatment or metabolic disorders. In cystic fibrosis (CF) patients, $P$. aeruginosa infects the respiratory tract chronically and causes the degradation of pulmonary function. This contributes to reduced life expectancy.

The ability of $P$. aeruginosa to occupy a wide range of habitats is due at least in part to its genetic versatility. The lungs of CF patients constitute a particular biotope

† Present address: Laboratoire de Bactériologie-Virologie-Hygiène, Unité de Bactériologie, Centre Hospitalier Universitaire Dupuytren, 87042 Limoges Cedex, France.

Abbreviations: CF, cystic fibrosis; ET, electrophoretic type; FIGE, fieldinversion gel electrophoresis; MLEE, multilocus enzyme electrophoresis; RAPD, random amplified polymorphic DNA. and it is plausible that this particular niche is generally occupied by a group of adapted $P$. aeruginosa strains.

A first step to elucidating the relationships between a bacterial population and its biotope is to study the genetic diversity of the population. The genetics of $P$. aeruginosa has not been extensively studied. However, there are data indicating high genetic diversity of populations of $P$. aeruginosa strains responsible for various infections of, for example, surgical wounds, the ear, the pulmonary tract and burns, or isolates recovered from the environment (Blanc et al., 1993; Griffith et al., 1989; Grüner et al., 1993; Picard et al., 1994).

The genetic diversity of populations of $P$. aeruginosa strains isolated from patients suffering from CF has been investigated in various ways. A large number of studies have used molecular methods including simple restriction endonuclease analysis (Maher et al., 1993), Southern blotting analysis using DNA probes encoding exotoxin A (Wolz et al., 1989) or pilin (Speert et al., 1989), rDNA RFLP (Denamur et al., 1991; Martin et al., 
1995) and DNA fingerprinting by pulsed-field electrophoresis (Grothues et al., 1988). Various patterns of chronic pulmonary colonization of CF patients by $P$. aeruginosa have been observed, particularly multiple resident strains (Struelens et al., 1993), a single strain or a periodically replaced dominant strain (Martin et al., 1995; Wolz et al., 1989). Most of the tools used for these studies are powerful typing methods for investigating nosocomial and epidemic infections but are not necessarily suitable for phylogenetic and population genetic studies.

Metabolic enzymes are central to the adaptation of a bacterium to its environment (Young et al., 1989). The analysis of the diversity of these enzymes by multilocus enzyme electrophoresis (MLEE) is a valuable and wellestablished way of studying the ecology of bacteria (Selander et al., 1986, 1987; Selander \& Musser, 1990). Here, we assess the polymorphism of 18 metabolic enzymes in a population of $314 \mathrm{P}$. aeruginosa strains isolated from French CF patients to determine the degree of variability of these strains, all living in the particular conditions of the pulmonary tract of CF patients. We also examined the association, if any, between ETs and patient characteristics and the properties of the bacteria.

\section{METHODS}

Patient population. In total, 314 isolates were recovered from 229 sputum samples from 87 CF patients (47 males and 40 females) attending the Centre Héliomarin (CHM) in Saint Trojan-les-Bains (patients 1-63 and 77), or the paediatric units of the Centre Hospitalier Universitaire (patients 64-76, 78-83, 85 and 86) and Bretonneau Hospital (patients 84 and 87), both in Tours, during a period of 3 years. The CF patients from whom the samples were collected constitute a heterogeneous population. Twenty-three patients were followed only at Tours and 12 only at St Trojan. The 52 others were hospitalized intermittently at CHM and regularly followed and treated by their district hospital: 21 patients at Necker hospital (Paris), 5 at Trousseau hospital (Paris), 4 at Nancy hospital, 3 at Angers hospital, 2 at Clermont-Ferrand hospital, 2 at Tours hospital, 2 at Nantes hospital, 2 at Rochefort hospital, and one each at Blois, Niort, Rambouillet, Melun, Roscoff, Soissons, Bordeaux, Boulogne-Billancourt, St Germain en Laye, Toulouse and Robert Debré (Paris) hospitals. Thirty-three of these 52 patients were colonized by $P$. aeruginosa before the first examination at CHM.

Patients were examined periodically to monitor their clinical status, at which time one or more sputum samples were obtained. The samples were cultured and strains representative of all morphotypes were saved. For 18 of the patients, multiple isolates were obtained at various intervals for 12-18 months.

Clinical evaluation of patients. A modification (Doershuk et al., 1965) of the Schwachmann-Kulcyzcki-Khaw scoring system (Schwachmann et al., 1965) was used to evaluate patient status. A best possible score of 25 is assigned for each of four categories: chest X-ray, general activity, nutrition and physical condition. There is thus a maximum total score of 100. The patients were assigned to five clinical condition groups: A, excellent (score, 86-100); B, good (71-85); C, moderate $(56-70)$; D, poor $(41-55)$; and E, weak $(<40)$.

Culture and storage of isolates. Respiratory specimens were cultured on trypticase-soy with $5 \%$ horse blood, chocolate (bioMérieux) and selective cetrimide (Diagnostics Pasteur) agars for $4 \mathrm{~d}$ at $37^{\circ} \mathrm{C}$. After examining the primary culture carefully, each different colony type was subcultured on a nutrient agar no. 1 plate (Unipath). Thus, 314 isolates were obtained from 229 sputa. Each strain was identified as $P$. aeruginosa on the basis of colony form, oxidase reaction, growth at $42{ }^{\circ} \mathrm{C}$, characteristic pigmentation on King A agar, and the appropriate response pattern in the API 20NE system (API, bioMérieux). Each of the 314 isolates was stored at $-80{ }^{\circ} \mathrm{C}$ in vitamin $\mathrm{K} 3$ broth (bioMérieux) containing $20 \%$ (v/v) glycerol.

Determination of colony form. At primary isolation, $P$. aeruginosa strains were classified into four morphological types after growth on nutrient agar no. 1 (Unipath) (Véron \& Berche, 1976). Smooth colonies were classified as small (sm), rough colonies as large (la), viscous colonies as mucoid (M), and the very small mucoid colonies as dwarf (d).

Serotyping. Serotypes were determined by slide agglutination with commercial O-antisera (Diagnostics Pasteur), according to the international typing scheme of Habs (1957) and the subtypes described by Véron (1961).

MLEE. Strains were grown overnight at $37^{\circ} \mathrm{C}$ in $150 \mathrm{ml}$ trypticase-soy broth, harvested by centrifugation, suspended in $1.5 \mathrm{ml} 50 \mathrm{mM}$ Tris/EDTA buffer $(\mathrm{pH} \mathrm{7.5)}$, and sonicated (Branson Sonifer Cell Disruptor, model 250, with microtip) for $30 \mathrm{~s}$ at $50 \%$ pulse, with ice-water cooling. Clear lysates were obtained by centrifugation at $16000 \mathrm{~g}$ for $20 \mathrm{~min}$ at $4{ }^{\circ} \mathrm{C}$ and stored at $-70{ }^{\circ} \mathrm{C}$.

Horizontal starch-gel electrophoresis and specific enzyme staining methods were used (Selander et al., 1986). Variation in electrophoretic mobility of the following 18 enzymes was assayed: alcohol dehydrogenase $(\mathrm{ADH})$, glutamate dehydrogenase (GDH), NADP-dependent glucose dehydrogenase (GLU), glucose-6-phosphate dehydrogenase (G6P), $\beta$-hydroxybutyrate dehydrogenase (HBD), isocitrate dehydrogenase (IDH), NAD-dependent malate dehydrogenase (MDH), mannitol-1-phosphate dehydrogenase (M1P), shikimate dehydrogenase (SKD), threonine dehydrogenase (THR), xanthine dehydrogenase $(\mathrm{XDH})$, acid phosphatase (ACP), glutamic oxaloacetic transaminase (GOT), indophenol oxidase (superoxide dismutase) (IPO), mannose phosphate dehydrogenase (MPI), nucleoside phosphorylase (NSP), phosphoglucose isomerase (PGI) and phosphoglucomutase (PGM). For each enzyme, mobility variants (electromorphs), numbered in decreasing order of rate of anodal migration, were equated with alleles at the corresponding structural gene locus; the absence of enzyme activity was attributed to a null allele. Each isolate was characterized by its combination of alleles at the 18 enzyme loci. Distinctive combinations of alleles, corresponding to multilocus genotypes, were designated as electrophoretic types (ETs) (Selander et al., 1986).

Statistical analysis. Genetic diversity ( $h$ ) among ETs at an enzyme locus was calculated from allele frequencies using the formula $h=n\left(1-\Sigma x_{\mathrm{i}}{ }^{2}\right) /(n-1)$, where $x_{\mathrm{i}}$ is the frequency of the $i$ th allele and $n$ is the number of ETs (Nei, 1977; Selander et al., 1986). Mean genetic diversity $(H)$ was calculated as the arithmetic mean of the $h$ values for all 18 loci. 
Table 1. Genetic diversity $(h)$ at 18 enzyme loci of 314 $P$. aeruginosa strains isolated from the respiratory tracts of 87 CF patients

The following nine loci were monomorphic, with a genetic diversity of 0: IDH, GDH, GLU, IPO, MPI, MDH, PGI, PGM, G6P.

\begin{tabular}{|lcc|}
\hline $\begin{array}{l}\text { Enzyme } \\
\text { locus }\end{array}$ & $\begin{array}{c}\text { No. of } \\
\text { alleles }\end{array}$ & $\begin{array}{c}\text { Genetic } \\
\text { diversity }(\boldsymbol{h})\end{array}$ \\
\hline ADH & 3 & $0 \cdot 228$ \\
GOT & 3 & $0 \cdot 228$ \\
NSP & 4 & $0 \cdot 331$ \\
HBD & 3 & $0 \cdot 228$ \\
SKD & 4 & $0 \cdot 493$ \\
THR & 3 & $0 \cdot 324$ \\
ACP & 2 & $0 \cdot 118$ \\
M1P & 3 & $0 \cdot 324$ \\
XDH & 2 & $0 \cdot 221$ \\
Mean $*$ & $2 \cdot 0$ & $0 \cdot 138$ \\
\hline
\end{tabular}

*Including the nine monomorphic loci.

\section{RESULTS}

The variation in ET representation was studied in three populations of strains: (i) in the total population, to investigate the genetic diversity of the collection and to study association between ET and colony morphology and serotype class; (ii) in the population composed of the first strain isolated from each of the 87 patients, to assess geographical variation and association between ET and age, sex or clinical condition of patients; (iii) in a collection of 228 strains isolated from the 18 of the 87 patients for whom more than one sample was collected over a period of $12-28$ months of evolution, to examine the temporal variation of strains.

\section{Genetic diversity of the total population}

In the total sample of 314 isolates, 9 of the 18 enzyme loci investigated were polymorphic, with 2-4 alleles. The other 9 loci were monomorphic (Table 1). The mean number of alleles per locus was $2 \cdot 0$.

Comparison of allele profiles identified a total of 17 ETs (Table 2), among which the mean genetic diversity per locus $(H)$ was $0 \cdot 138 \pm 0.038$ (Table 1 ). Of the $314 \mathrm{CF}$ isolates, $290(92 \%)$ were either ET1 $(n=127$ or $40 \%)$ or ET2 $(n=163$ or $52 \%)$, which differed only at the SKD locus. Of the remaining $15 \mathrm{ETs}$, only four (ETs 3, 4,5 and 13) were represented by more than one isolate (range, 2-5) (Table 2).

Like ET1, 11 of the other 16 ETs (ETs 3-5, 7, 9-13, 16 and 17) had the $S_{K D}{ }^{1}$ allele. Each only differed from ET1 at a single locus, in two cases by possession of a null allele. ETs 14 and 15 had the SKD ${ }^{2}$ allele like ET2 and only differed from that ET2 at single loci. ET6 differed from ET1 and ET2 only in having an SKD ${ }^{4}$ allele. ET4 and ET8 were the most distinctive, differing from the two common ETs at four and three loci, respectively (Table 2). ATCC 10145, the $P$. aeruginosa type strain, is of ET1.

Table 2. Allele profiles of 17 ETs of $P$. aeruginosa isolates recovered from CF patients

\begin{tabular}{|c|c|c|c|c|c|c|c|c|c|c|c|}
\hline \multirow[t]{2}{*}{ ET } & \multirow[t]{2}{*}{$\begin{array}{l}\text { Reference } \\
\text { strain }\end{array}$} & \multirow[t]{2}{*}{$\begin{array}{l}\text { No. of } \\
\text { isolates }\end{array}$} & \multicolumn{9}{|c|}{$\begin{array}{l}\text { Allele at indicated polymorphic } \\
\text { enzyme locus" }\end{array}$} \\
\hline & & & $\mathrm{ADH}$ & GOT & NSP & HBD & SKD & THR & ACP & M1P & $\mathrm{XDH}$ \\
\hline 1 & PS1 & 127 & 2 & 2 & 2 & 2 & 1 & 1 & 1 & 2 & 1 \\
\hline 2 & PS2 & 163 & 2 & 2 & 2 & 2 & 2 & 1 & 1 & 2 & 1 \\
\hline 3 & PS10 & 5 & 2 & 2 & 2 & 2 & 1 & 1 & 2 & 2 & 1 \\
\hline 4 & PS12 & 3 & 3 & 2 & 1 & 2 & 1 & 1 & 1 & 3 & 2 \\
\hline 5 & PS28 & 2 & 2 & 2 & 2 & 0 & 1 & 1 & 1 & 2 & 1 \\
\hline 6 & PS36 & 1 & 2 & 2 & 2 & 2 & 4 & 1 & 1 & 2 & 1 \\
\hline 7 & PS37 & 1 & 2 & 2 & 2 & 2 & 1 & 2 & 1 & 2 & 1 \\
\hline 8 & PS46 & 1 & 2 & 1 & 2 & 2 & 3 & 2 & 1 & 2 & 1 \\
\hline 9 & PS62 & 1 & 1 & 2 & 2 & 2 & 1 & 1 & 1 & 2 & 1 \\
\hline 10 & PS70 & 1 & 2 & 2 & 2 & 2 & 1 & 1 & 1 & 3 & 1 \\
\hline 11 & PS78 & 1 & 2 & 2 & 2 & 2 & 1 & 1 & 1 & 1 & 1 \\
\hline 12 & PS80 & 1 & 2 & 2 & 2 & 2 & 1 & 1 & 1 & 2 & 2 \\
\hline 13 & S137 & 3 & 2 & 2 & 2 & 1 & 1 & 1 & 1 & 2 & 1 \\
\hline 14 & S175 & 1 & 2 & 2 & 2 & 2 & 2 & 0 & 1 & 2 & 1 \\
\hline 15 & S197 & 1 & 2 & 2 & 0 & 2 & 2 & 1 & 1 & 2 & 1 \\
\hline 16 & S221 & 1 & 2 & 2 & 3 & 2 & 1 & 1 & 1 & 2 & 1 \\
\hline 17 & PSA3 & 1 & 2 & 0 & 2 & 2 & 1 & 1 & 1 & 2 & 1 \\
\hline
\end{tabular}

*Nine other enzyme loci were monomorphic (see legend to Table 1). 
Table 3. Distribution of 314 clinical isolates of ET1 and ET2 with respect to bacterial properties

\begin{tabular}{|c|c|c|c|c|c|}
\hline \multirow[t]{2}{*}{ Character and category } & \multicolumn{3}{|c|}{ No. of isolates } & \multirow[t]{2}{*}{$\chi^{2}$} & \multirow[t]{2}{*}{$P$} \\
\hline & ET1 & ET2 & $\begin{array}{l}\text { Other } \\
\text { ETs }\end{array}$ & & \\
\hline \multicolumn{6}{|l|}{$\begin{array}{l}\text { Colonial morphology } \\
\text { class }\end{array}$} \\
\hline la & 30 & 25 & 5 & & \\
\hline$M+d$ & 21 & 61 & 9 & $16 \cdot 71$ & $0 \cdot 002$ \\
\hline sm & 76 & 77 & 10 & & \\
\hline \multicolumn{6}{|l|}{ Bacterial serotype class } \\
\hline $\mathrm{PAG}^{*}$ & 74 & 43 & 11 & $31 \cdot 14$ & $<0 \cdot 001$ \\
\hline $\mathrm{O} 1, \mathrm{O} 3, \mathrm{O} 6$ and $\mathrm{O} 13$ & 15 & 30 & 2 & & \\
\hline Non-typable & 38 & 90 & 11 & & \\
\hline
\end{tabular}

*Agglutination with polyvalent antisera.

Table 4. Geographical variation in ET composition of populations, based on single isolates from $87 \mathrm{CF}$ patients

\begin{tabular}{|lcrcr|}
\hline Locality* & $\begin{array}{c}\text { Total no. } \\
\text { of } \\
\text { isolates }\end{array}$ & \multicolumn{3}{c|}{ No. $(\%)$ of isolates of } \\
\cline { 3 - 5 } & & ET1 & ET2 & $\begin{array}{l}\text { Other } \\
\text { ETs }\end{array}$ \\
\hline CHM St Trojan & 12 & $4(33)$ & $8(67)$ & $0(0)$ \\
Necker (Paris) & 21 & $3(14)$ & $15(72)$ & $3(14)$ \\
Trousseau (Paris) & 5 & $1(20)$ & $2(40)$ & $2(40)$ \\
Tours & 23 & $15(66)$ & $4(17)$ & $4(17)$ \\
17 Others & 26 & $13(50)$ & $9(35)$ & $4(15)$ \\
\hline
\end{tabular}

*See Methods for details.

\section{Association of ET1 and ET2 with colony morphology and with serotype class}

Of the 314 clinical isolates, 163 were small (sm), 60 large (la), 81 mucoid (M) and $10 \mathrm{dwarf}(\mathrm{d})$. The distribution of the colony types into ET1 and ET2 was significantly different (Table 3 ) : 78\% of the mucoid strains were in ET2 whereas the other colony types were identically distributed in ET1 and ET2.

One hundred and fifty-seven sputa exhibited only one colony type and $72(31 \%)$ more than one: one sputum gave colonies with four different morphologies, 11 showed three and the others two. Therefore, a total of 157 isolates corresponding to these various morphologies were studied. Isolates belonging to 57 of these 72 sputa were of the same ET whatever the colonial form (20 in ET1 and 37 in ET2). Only 15 sputa, from 9 patients, gave strains with different colony morphologies belonging to two or three different ETs. However, these strains were closely related. They belonged to the three most frequent ETs and/or differed at one locus only, except for one patient for whom the strains isolated from one sputum sample were ET4 and ET13, which differ by one allele at each of five loci.

Of the 314 isolates, 139 were serologically non-typable, 128 agglutinated with polyvalent antisera (PAG), and 47 could be typed as O1, O3, O6 or O13. The distributions of strains of ET1 and ET2 among these three serotype classes were significantly different (Table 3). Disproportionately more isolates of ET1 were PAG and more isolates of ET2 were non-typable.

\section{Geographical variation in ET representation and absence of association between ET and sex, age or clinical condition of patients}

To assess the difference in ET representation between patients attending the principal care centres participating, the first isolate collected from each patient was selected to represent each of the 87 patients and was analysed. There was a significant difference between centres, mainly due to a preponderance of ET2 at Necker and of ET1 at Tours (Table 4, $P<0 \cdot 01$ ).

The distributions of numbers of isolates of ET1 and ET2 
Table 5. Distribution of isolates of ET1 and ET2 with respect to patient characteristics

\begin{tabular}{|c|c|c|c|c|c|}
\hline \multirow[t]{2}{*}{ Character and category } & \multicolumn{3}{|c|}{ No. of isolates } & \multirow[t]{2}{*}{$\chi^{2}$} & \multirow[t]{2}{*}{$P$} \\
\hline & ET1 & ET2 & $\begin{array}{l}\text { Other } \\
\text { ETs }\end{array}$ & & \\
\hline \multicolumn{6}{|l|}{ Sex } \\
\hline Male & 20 & 20 & 7 & $0 \cdot 12$ & $0 \cdot 94$ \\
\hline Female & 17 & 18 & 5 & & \\
\hline \multicolumn{6}{|l|}{ Age (years) } \\
\hline $1-17$ & 29 & 31 & 11 & $1 \cdot 07$ & 0.59 \\
\hline $18-34$ & 8 & 7 & 1 & & \\
\hline \multicolumn{6}{|l|}{ Clinical condition* } \\
\hline$A$ and $B$ & 21 & 14 & 6 & $3 \cdot 03$ & $0 \cdot 22$ \\
\hline $\mathrm{C}, \mathrm{D}$ and $\mathrm{E}$ & 16 & 24 & 6 & & \\
\hline
\end{tabular}

*See Methods for category definitions.

with respect to sex, age and clinical condition of the 87 patients are shown in Table 5. No significant associations were detected.

\section{Temporal variation in ET representation among isolates from individual patients}

Temporal variation in ET representation was analysed for 18 patients (including three pairs of siblings) from whom more than one isolate (range, 4-28) was recovered from sputa collected at intervals over 12-28 months (Table 6).
Six of the 18 patients (L, N, R, H, U and V) yielded exclusively strains of either ET1 or ET2 and showed no temporal variation in ET representation throughout the period investigated.

For the 12 other patients, temporal change was observed. Patients T, Q, K, F, O, J, S and M (Table 6) had two types of strains in some sputa. Patients G, P, K, X, W, F, $\mathrm{O}, \mathrm{J}$ and $\mathrm{S}$ (Table 6) had strains belonging to different ETs at different times. For all these patients, it is possible that each type of strain could have been present throughout the study period but that not all were isolated from each sample. This may be the case, especially if one type was predominant or if colonies on the primary plate had the same morphology. Nevertheless, in most of the patients, strains of ET1 and/or of ET2 were preponderant.

Three pairs of sibling ( $\mathrm{N}$ and $\mathrm{G}$; $\mathrm{Q}$ and $\mathrm{R}$; and $\mathrm{J}$ and $\mathrm{S}$ ) were investigated. ET representation was very similar within each pair (Table 6). The only divergence was the appearance of ET3 in patient $S$, but not in sibling $\mathrm{J}$, at the end of the study period.

\section{DISCUSSION}

The objective of this work was to investigate the genetic diversity within the $P$. aeruginosa population isolated from patients suffering from CF. We used MLEE, which has long been a standard method in eukaryotic population genetics and systematics. It has been used in largescale studies to estimate the genetic diversity and structure of natural populations of a variety of bacteria and has been extensively validated for these purposes

Table 6. Temporal variation in ET representation of strains recovered from 18 individual CF patients

\begin{tabular}{|c|c|c|c|c|c|c|c|c|c|c|c|c|c|c|c|c|c|c|c|c|}
\hline \multirow[t]{2}{*}{ Patient } & \multicolumn{2}{|c|}{ No. of } & \multicolumn{18}{|c|}{ ETs of strains in successive samples (sputa) } \\
\hline & Months & Strains & 1 & 2 & 3 & 4 & 5 & 6 & 7 & 8 & 9 & 10 & 11 & 12 & 13 & 14 & 15 & 16 & 17 & 18 \\
\hline $\mathrm{L}$ & 24 & 20 & 1 & 1 & 1 & 1 & 1 & 1 & 1 & 1 & 1 & 1 & 1 & 1 & 1 & & & & & \\
\hline$N^{*}$ & 13 & 4 & 1 & 1 & 1 & & & & & & & & & & & & & & & \\
\hline$G^{*}$ & 13 & 4 & 1 & 1 & 13 & & & & & & & & & & & & & & & \\
\hline $\mathrm{T}$ & 18 & 6 & 1,2 & 2 & 2 & 2 & & & & & & & & & & & & & & \\
\hline $\mathrm{Q} \dagger$ & 13 & 7 & 2,15 & 2 & 2 & 2 & & & & & & & & & & & & & & \\
\hline $\mathrm{R} \dagger$ & 13 & 7 & 2 & 2 & 2 & 2 & & & & & & & & & & & & & & \\
\hline $\mathrm{H}$ & 13 & 7 & 2 & 2 & 2 & 2 & & & & & & & & & & & & & & \\
\hline $\mathrm{U}$ & 14 & 11 & 2 & 2 & 2 & 2 & 2 & 2 & & & & & & & & & & & & \\
\hline $\mathrm{V}$ & 28 & 9 & 2 & 2 & 2 & 2 & 2 & 2 & 2 & 2 & & & & & & & & & & \\
\hline $\mathrm{P}$ & 16 & 24 & 2 & 2 & 14 & 2 & 2 & 2 & 2 & 2 & 2 & 2 & 2 & 2 & 2 & 2 & 2 & 2 & 2 & \\
\hline $\mathrm{K}$ & 26 & 28 & 2 & 2 & 2 & 2 & 2 & 2 & 2 & 2 & 1,2 & 2 & 1 & 1 & 2 & 1 & 1 & 1 & 1,2 & 1 \\
\hline$X$ & 18 & 11 & 2 & 2 & 2 & 1 & 1 & 1 & 1 & 1 & 2 & 1 & 1 & & & & & & & \\
\hline W & 13 & 10 & 2 & 2 & 2 & 1 & 1 & & & & & & & & & & & & & \\
\hline $\mathrm{F}$ & 24 & 21 & 2 & 1 & 1,2 & 2 & 2 & 1 & 2 & 1 & 1 & 1,3 & 1 & 1,2 & & & & & & \\
\hline $\mathrm{O}$ & 22 & 20 & 2 & 1 & 2 & 1 & 1,2 & 1 & 2 & 2 & 2 & 1 & 2 & 2 & 2 & 2 & 1 & & & \\
\hline $\mathrm{J} \neq$ & 24 & 19 & 1 & 2 & 1,2 & 2 & 2 & 2 & 1 & 1 & 1 & 1,2 & 16 & 1 & 2 & & & & & \\
\hline Sł & 22 & 16 & 1 & 1 & 1,2 & 1 & 2 & 2 & 1 & 2 & 2 & 1 & 2,3 & 2,3 & & & & & & \\
\hline M & 12 & 4 & 4 & 4,13 & & & & & & & & & & & & & & & & \\
\hline
\end{tabular}

*Sibling pair. †Twin brothers. ‡Sibling pair. 
Table 7. Variation in ribotype among ETs based on single isolates from 87 CF patients

\begin{tabular}{|c|c|c|c|c|c|c|c|c|c|c|}
\hline \multirow[t]{2}{*}{ Sample } & \multirow{2}{*}{$\begin{array}{l}\text { No. of } \\
\text { isolates }\end{array}$} & \multicolumn{9}{|c|}{ No. of isolates of indicated ribotype } \\
\hline & & 1 & 2 & 3 & 4 & 5 & 6 & 7 & 8 & Other \\
\hline ET1 & 37 & 8 & 9 & & 3 & 1 & & 2 & 2 & $12 *$ \\
\hline ET2 & 38 & 20 & & 8 & & 2 & 3 & & & $5 \dagger$ \\
\hline ET-1-like ETsł & 10 & 1 & 2 & 1 & & & & & & $6 \mathbb{S}$ \\
\hline Other ETs $\|$ & 2 & & & & & & & & & 29 \\
\hline
\end{tabular}

* Ribotypes 11, 15, 16, 18, 19, 23, 24, 31, 32 and 33.

† Ribotypes 9, 26, 27, 28 and 30.

‡ETs $3-5,7$ and 9-12.

\Ribotypes 10, 13, 14, 17, 20 and 22 .

\| ETs 6 and 8.

g Ribotypes 12 and 29.

(Selander \& Musser, 1990; Selander et al., 1986). For several organisms, estimates of genetic distance between pairs of strains based on electrophoresis of metabolic enzymes have been shown to be strongly correlated with estimates of nucleotide sequence divergence as assessed by hybridization of DNA (Selander \& Musser, 1990; Quentin et al., 1993) or 16S RNA (Quentin et al., 1996). MLEE has also been used to study the intraspecies genetic structure of many species (Musser et al., 1988, 1989, 1991; Quentin et al., 1995; Selander et al., 1990) and is able to define virulent clone families within species. It is therefore a solid basis for determining genomic characteristics specific to invasive isolates (Chatellier et al., 1996).

Our results indicate that there is little genetic diversity at 18 loci for metabolic enzymes in a population of French $P$. aeruginosa $\mathrm{CF}$ strains. Three hundred and fourteen French CF isolates were studied and only $50 \%$ of the loci were polymorphic. Although 17 ETs were distinguished, $H$ was only 0.138 and $92 \%$ of the strains clustered in two ETs. These findings contrast with those of an MLEE analysis of isolates recovered in an oncology ward in the Michael Reese Hospital, in Chicago, Illinois (Griffith et al., 1989). For the 172 isolates examined, $83 \%$ of the loci were polymorphic, 64 ETs were distinguished, and $H$ for the ETs was 0.229. Other studies have also reported genetic heterogeneity of clinical isolates of $P$. aeruginosa strains (Levin et al., 1984; Picard et al., 1994).

There are many possible explanations of why French CF isolates of $P$. aeruginosa belong to two major groups of strains. One is that the CF patients were repeatedly hospitalized in the same centres and may have been cross-colonized. The correlation between ET distribution (ET1 and ET2) and geographical origin of the strains argues for this hypothesis. However, the two most prevalent ETs differed at only the SKD locus. And in addition, it is difficult to imagine that all 87 patients, who were treated at 20 different hospitals scattered across 29 of the 95 departments of France, did not encounter genetically diverse $P$. aeruginosa strains in their environment.

Another possible explanation of the existence of the two major clusters of strains is that particular groups of $P$. aeruginosa have been selected for their ability to adapt to the bronchopulmonary environment and to survive on the surface of the respiratory tract epithelium. The existence of strains specifically adapted to CF airways does not exclude the possibility that they are transmitted by cross-colonization and are responsible for other illnesses.

The relative homogeneity and stability of strains repeatedly recovered from sputa collected from 18 patients over periods of from 12 to 28 months (Table 6), and the absence of associations between ET distribution and the clinical status of patients, indicate that deterioration of the clinical status was not due to superinfection or to the emergence of particular virulent clones. Probably, the expression of virulence factors or the host reaction are more important to lung degradation than superinfections or changes in strain population.

Some studies exploring other parts of the genome of $P$. aeruginosa isolates from $\mathrm{CF}$ airways argue for heterogeneity and variability of isolates in the pulmonary flora of chronically infected CF patients. For example, DNA fingerprinting using arbitrarily primed polymerase chain reactions (AP-PCR) (Renders et al., 1997) or random amplified polymorphic DNA fingerprintingPCR (RAPD-PCR) (Hoogkamp-Korstanje et al., 1995) give a large variety of patterns. Macrorestriction analysis with pulsed-field gel electrophoresis (PFGE) also detected the presence of multiple genetic differences between the genomes of different $P$. aeruginosa isolates (Römling et al., 1994; Struelens et al., 1993). RFLP of the rRNA gene region is consistent with heterogeneity of the rRNA operon (Bennekov et al., 1996). In a previous study (Martin et al., 1995), we characterized the genetic heterogeneity of rRNA operons of 87 of the P. aeruginosa strains included in this work using four restriction enzymes (BamHI, ClaI, EcoRI and PstI). Each isolate 
was from a different CF patient. Ribotyping and MLEE analysis give different views of the structure of the population of strains studied (Table 7). There were many more ribotypes ( 31 ribotypes) than ETs (15 ETs, with $92 \%$ of the strains in two ETs) in this group of strains, and strains in one ET were of different ribotypes. The inconsistencies between the results of different studies may indicate a high gene flow rate within $P$. aeruginosa isolates as previously suggested (Denamur et al., 1993).

Apparent disagreement between results of various studies may be also due in part to the difficulties in measuring the degree of relatedness of strains exhibiting different patterns and in evaluating the diversity of a population by DNA typing methods. The recombination rate or other genetic events in a species may vary between genes according to the function of these genes (Smith \& Selander, 1990; Nelson \& Selander, 1992). It is possible that the particular conditions in the CF pulmonary tract select particular traits in genes encoding metabolic enzymes involved in biochemical pathways determining the degree of adaptation of the bacteria to the environment. Non-coding DNA sequences, or genes encoding virulence factors or cell surface proteins interacting with the host reaction during the long evolution of the CF infection, may be more susceptible to mutation, recombination or horizontal genetic transfer. The genetic polymorphism resulting from these multiple genetic events would be detected by tools exploring the total genome such as RAPD or FIGE.

In conclusion, our results suggest that limited groups of $P$. aeruginosa strains are able to colonize CF patients. To assess the position of CF $P$. aeruginosa strains within the far-flung world of $P$. aeruginosa species, isolates from other sources and from other geographical origins should be examined. In addition, a better understanding of the way in which different parts of the genome of CF $P$. aeruginosa isolates vary may help elucidate the particular relationship that exists between CF patients and this bacterium.

\section{ACKNOWLEDGEMENTS}

We thank Mrs Sheila Plock, Stephanie Spiegelmyer and Jennifer Deerborn for their technical assistance. We thank Professor André Audurier (Tours) and Drs Sylvie Frougier and Florence Landais (St Pierre d'Oléron) for supplying the strains, and Drs Sophie Marchand and Françoise Varaigne (Tours) for providing clinical data.

This research was supported by grants from the association 'Anjou Mucoviscidose' (to R.Q.), and in part by grant AI22144 from the national Institutes of Health (to R.K.S.).

\section{REFERENCES}

Bennekov, T., Colding, H., Ojeniyi, B., Bentzon, M. \& Høiby, N. (1996). Comparison of ribotyping and genome fingerprinting of Pseudomonas aeruginosa isolates from cystic fibrosis patients. $J$ Clin Microbiol 34, 202-204.

Blanc, D. S., Siegrist, H. H., Sahli, R. \& Francioli, P. (1993). Ribotyping of Pseudomonas aeruginosa: discriminatory power and usefulness as a tool for epidemiological studies. J Clin Microbiol 31, 71-77.

Chatellier, S., Huet, H., Kenzi, S., Rosenau, A., Geslin, P. \& Quentin, R. (1996). Genetic diversity of rRNA operons of unrelated Streptococcus agalactiae strains isolated from cerebrospinal fluid of neonates suffering from meningitis. J Clin Microbiol 34, 2741-2747.

Denamur, E., Picard, B., Goullet, P., Bingen, E., Lambert, N. \& Elion, J. (1991). Complexity of Pseudomonas aeruginosa infection in cystic fibrosis: combined results from esterase electrophoresis and rDNA restriction fragment length polymorphism analysis. Epidemiol Infect 106, 531-539.

Denamur, E., Picard, B., Decoux, G., Denis, J. B. \& Elion, J. (1993). The absence of correlation between alloenzyme and $r r n$ analysis indicates a high gene flow rate within human clinical Pseudomonas aeruginosa isolates. FEMS Microbiol Lett 110, 275-280.

Doershuk, C. F., Matthews, L. W., Tucker, A. S. \& Spector, S. (1965). Evaluation of a prophylactic and therapeutic program for patients with cystic fibrosis. Pediatrics 36, 675-688.

Griffith, S. J., Nathan, C., Selander, R. K., Chamberlin, W., Gordon, S., Kabins, S. \& Weinstein, R. A. (1989). The epidemiology of Pseudomonas aeruginosa in oncology patients in a general hospital. J Infect Dis 160, 1030-1036.

Grothues, D., Koopmann, U., von der Hardt, H. \& Tümmler, B. (1988). Genome fingerprinting of Pseudomonas aeruginosa indicates colonization of cystic fibrosis siblings with closely related strains. J Clin Microbiol 26, 1973-1977.

Grüner, E., Kropec, A., Hubner, J., Altwegg, M. \& Daschner, F. (1993). Ribotyping of Pseudomonas aeruginosa strains isolated from surgical intensive care patients. J Infect Dis 167, 1216-1220.

Habs, I. (1957). Untersuchungen über die O-Antigene von Pseudomonas aeruginosa. Z Hyg Infektionskr 144, 218-228.

Hoogkamp-Korstanje, J. A. A., Meis, J. F. G. M., Kissing, J., van der Laag, J. \& Melchers, W. J. G. (1995). Risk of cross-colonization and infection by Pseudomonas aeruginosa in a holiday camp for cystic fibrosis patients. J Clin Microbiol 33, 572-575.

Levin, M. H., Weinstein, R. A., Nathan, C., Selander, R. K., Ochman, H. \& Kabins, S. A. (1984). Association of infection caused by Pseudomonas aeruginosa serotype O11 with intravenous abuse of pentazocine mixed with tripelennamine. J Clin Microbiol 20, 758-762.

Maher, W. E., Kobe, M. \& Fass, R. J. (1993). Restriction endonuclease analysis of clinical Pseudomonas aeruginosa strains: useful epidemiologic data from a simple and rapid method. J Clin Microbiol 31, 1426-1429.

Martin, C., Aït Ichou, M., Massicot, P., Goudeau, A. \& Quentin, R. (1995). Genetic diversity of Pseudomonas aeruginosa strains isolated from patients with cystic fibrosis revealed by restriction fragment length polymorphism of the ribosomal RNA gene region. J Clin Microbiol 33, 1461-1466.

Musser, J. M., Kroll, J. S., Moxon, E. R. \& Selander, R. K. (1988). Evolutionary genetics of the encapsulated strains of Haemophilus influenzae. Proc Natl Acad Sci USA 85, 7758-7762.

Musser, J. M., Mattingly, S. J., Quentin, R., Goudeau, A. \& Selander, R. K. (1989). Identification of a high-virulence clone of type III Streptococcus agalactiae (group B Streptococcus) causing invasive neonatal disease. Proc Natl Acad Sci USA 86, 4731-4735.

Musser, J. M., Hauser, A. R., Kim, M. H., Schlievert, P. M., Nelson, K. \& Selander, R. K. (1991). Streptococcus pyogenes causing toxicshock-like syndrome and other invasive diseases: clonal diversity and pyrogenic exotoxin expression. Proc Natl Acad Sci USA 88, 2668-2672. 
Nei, M. (1977). F-statistics and analysis of gene diversity in subdivided populations. Ann Hum Genet 41, 225-233.

Nelson, K. \& Selander, R. K. (1992). Evolutionary genetics of the proline permease gene $(p u t P)$ and the control region of the proline utilization operon in populations of Salmonella and Escherichia coli. J Bacteriol 174, 6686-6695.

Picard, B., Denamur, E., Barakat, A., Elion, J. \& Goullet, P. (1994). Genetic heterogeneity of Pseudomonas aeruginosa clinical isolates revealed by esterase electrophoretic polymorphism and restriction fragment length of the ribosomal RNA gene region. J Med Microbiol 40, 313-322.

Quentin, R., Martin, C., Musser, J. M., Pasquier-Picard, N. \& Goudeau, A. (1993). Genetic characterization of a cryptic genospecies of Haemophilus causing urogenital and neonatal infections. J Clin Microbiol 31, 1111-1116.

Quentin, R., Huet, H., Wang, F.-S., Geslin, P., Goudeau, A. \& Selander, R. K. (1995). Characterization of Streptococcus agalactiae strains by multilocus enzyme genotype and serotype: identification of multiple virulent clone families that cause invasive neonatal disease. J Clin Microbiol 33, 2576-2581.

Quentin, R., Ruimy, R., Rosenau, A., Musser, J. M. \& Christen, R. (1996). Genetic identification of cryptic genospecies of Haemophilus causing urogenital and neonatal infections by PCR using specific primers targeting genes coding for $16 \mathrm{~S}$ rRNA. J Clin Microbiol 34, 1380-1385.

Renders, N. H. M., Sijmons, M. A. F., van Belkum, A., Overbeek, S. E., Mouton, J. W. \& Verbrugh, H. A. (1997). Exchange of Pseudomonas aeruginosa strains among cystic fibrosis patients. Res Microbiol 148, 447-454.

Römling, U., Fiedler, B., Boßhammer, J., Grothues, D., Greipel, J., von der Hardt, H. \& Tümmler, B. (1994). Epidemiology of chronic Pseudomonas aeruginosa infections in cystic fibrosis. J Infect Dis 170, 1616-1621.

Schwachmann, H., Kulczycki, L. L. \& Khaw, K. T. (1965). Studies in cystic fibrosis: a report on sixty-five patients over 17 years of age. Pediatrics 36, 689-699.

Selander, R. K., \& Musser, J. M. (1990). Population genetics of bacterial pathogenesis. In Molecular Basis of Bacterial Pathogenesis, pp. 11-36. Edited by B. H. Iglewski \& V. L. Clark. San Diego: Academic Press.
Selander, R. K., Caugant, D. A., Ochman, H., Musser, J. M., Gilmour, M. N. \& Whittman, T. S. (1986). Methods of multilocus enzyme electrophoresis for bacterial population genetics and systematics. Appl Environ Microbiol 51, 873-884.

Selander, R. K., Musser, J. M., Caugant, D. A., Gilmour, M. N. \& Whittman, T. S. (1987). Population genetics of pathogenic bacteria. Microb Pathog 3, 1-7.

Selander, R. K., Beltran, P., Smith, N. H., Barker, R. M., Crichton, P. B., Old, D. C., Musser, J. M. \& Whittman, T. S. (1990). Genetic population structure, clonal phylogeny, and pathogenicity of Salmonella paratyphi B. Infect Immun 58, 1891-1901.

Smith, N. H. \& Selander, R. K. (1990). Sequence invariance of the antigen-coding central region of the phase 1 flagellar filament gene (flicC) among strains of Salmonella typhimurium. J Bacteriol 172, 603-609.

Speert, D. P., Campbell, M. E., Farmer, S. W., Volpel, K., Joffe, A. M. \& Paranchych, W. (1989). Use of a pilin gene probe to study molecular epidemiology of Pseudomonas aeruginosa. J Clin Microbiol 27, 2589-2593.

Struelens, M. J., Schwam, V., Deplano, A. \& Baran, D. (1993). Genome macrorestriction analysis of diversity and variability of Pseudomonas aeruginosa strains infecting cystic fibrosis. J Clin Microbiol 31, 2320-2326.

Véron, M. (1961). Sur l'agglutination de Pseudomonas aeruginosa: subdivision des groupes antigéniques $\mathrm{O}: 2$ et $\mathrm{O}: 5$. Ann Inst Pasteur 101, 456-460.

Véron, M. \& Berche, P. (1976). Virulence et antigènes de Pseudomonas aeruginosa. Bull Inst Pasteur 74, 295-337.

Wolz, C., Kiosz, G., Ogle, J. W., Vasil, M. L., Schaad, U., Botzenhart, K. \& Döring, G. (1989). Pseudomonas aeruginosa cross-colonization and persistence in patients with cystic fibrosis. Use of a DNA probe. Epidemiol Infect 102, 205-214.

Young, J. P. (1989). The population genetics of bacteria. In Genetics of Bacterial Diversity, pp. 417-438. Edited by D. A. Hopwood \& K. E. Chater. London: Academic Press.

Received 3 November 1998; revised 28 April 1999; accepted 13 May 1999. 